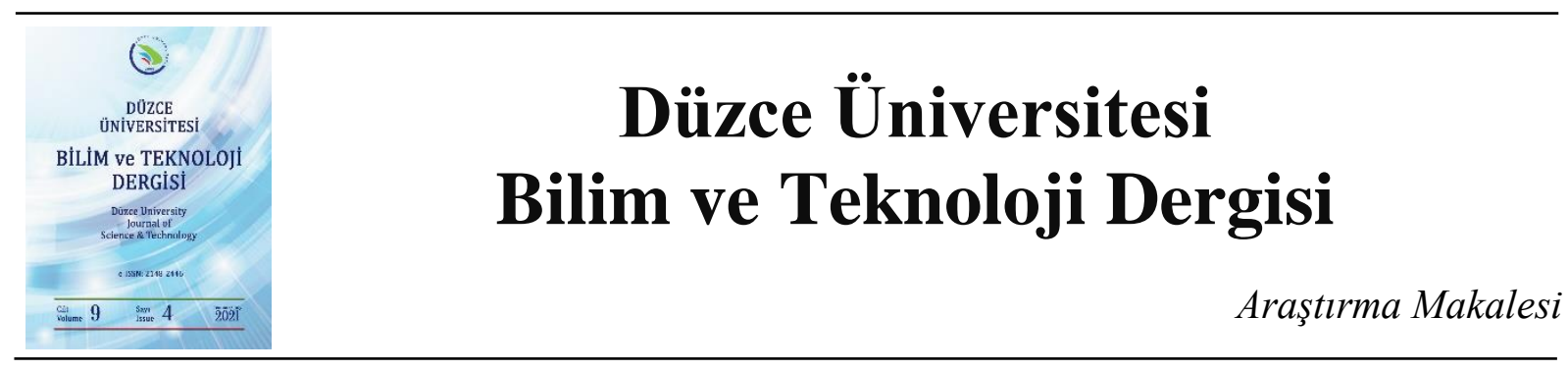

\title{
Araç Cüzdanı: Motorlu Araçların Teknik Servis ve Bakım Kayıtlarının Blokzinciri Üzerinde Yönetilmesi
}

\author{
Mustafa TANRIVERDİ ${ }^{a}{ }^{*}$, (D) Mevlüt UYSAL ${ }^{a}$, (D) Mutlu Tahsin ÜSTÜNDAĞ ${ }^{\mathrm{b}}$, (D) Zafer AYAZ ${ }^{\mathrm{a}}$ \\ ${ }^{a}$ Bilgi İşlem Daire Başkanlı̆̆l, Gazi Üniversitesi, Ankara, TÜRKIYE \\ ${ }^{b}$ Bilgisayar ve Öğretim Teknolojileri Eğitimi, Gazi Üniversitesi, Ankara, TÜRKIYYE \\ * Sorumlu yazarın e-posta adresi: mustafatanriverdi@gmail.com
}

DOI: 10.29130/dubited.904757

\begin{abstract}
$\underline{\mathrm{O} Z}$
Günlük hayatta edindiğimiz tecrübeler bize özellikle ikinci el motorlu araç satışlarında, araçların geçmişteki teknik servis ve bakım kayıtları gibi bilgilere erişim noktasında sorun yaşandığını göstermiştir. Yaşanan bu zorluk çeşitli mağduriyetlere neden olmaktadır. Blokzinciri, özellikleri ve sunduğu firsatlar sayesinde karşılaşılan bu sorunun üstesinden gelmek için uygun bir teknoloji olarak değerlendirilebilir. Bu çalışmada her bir araç için özel blokzinciri ağı içerisinde bir hesap tanımlanması ve araç bakım servislerinin, parça sağlayıcıların ve sigorta şirketlerinin de katılımcı olarak bu ağa eklenmesi yöntemine dayanan bir çözüm önerilmektedir. Sunulan çözümde servis noktalarındaki uygulamalar sayesinde araçlara ait bakım, parça değişimi, tamirat gibi işlemlere ilişkin kayıtların blokzinciri hesabına kaydedilmesi ve bu bilgilerin blokzinciri ağında dağıtık, şeffaf ve değiştirilemez olarak saklanması planlanmıştır. Sunulan çözüm sayesinde servis noktalarının ve müşterilerin araçların geçmiş dönemlerdeki servis kayıtlarına şeffaf ve güvenli bir şekilde erişimi sağlanabilecektir.
\end{abstract}

Anahtar Kelimeler: Blokzinciri, Araç cüzdanı, Araç alım satımı

\section{Vehicle Wallet: Managing Technical Service and Maintenance Records of Motor Vehicles on Blockchain}

\begin{abstract}
The experiences we have gained in daily life shows that there are some problems about accessing to information such as past technical service and maintenance records of the vehicles, especially in terms of sales of used motor vehicles. This difficulty causes various grievances. Blockchain, thanks to its features and opportunities, can be considered as a suitable technology to overcome this problem. In this study, a solution is proposed which is based on defining an account in the private blockchain network for each vehicle and adding vehicle maintenance services, parts providers and insurance companies to this network as a participant. In the presented solution, it is planned that, the records of the operations such as maintenance, replacement of parts and list of repairments are recorded in the blockchain account via the applications at the service points and this information is stored in the blockchain network distributed, transparent and immutable. The solution provides both service points and customers to access the previous service records of the vehiclesin a transparent and secure way.
\end{abstract}

Keywords: Blockchain, Vehicle wallet, Vehicle trade 


\section{GİRIS}

Motorlu araçlar yaklaşık yüz yıldan beri ulaşım, ticaret, sanayi ve hobi amacıyla yaygın olarak kullanılmaktadır. Son yıllarda kullanım alanı ve seçenekleri artan motorlu araçlar, tüketicilerin günlük hayatları için bir ihtiyaç haline gelmiştir. Özellikle son zamanlarda tecrübe ettiğimiz koronavirüs (COVID-19) pandemisi nedeniyle insanlar ulaşım için toplu taşıma yerine özel araçlarını kullanma eğilimindedir. Bu dönemde araç üreticilerinin üretimi ciddi oranda azaltması veya durdurması nedeniyle ikinci el piyasası ciddi oranda değer kazanmıştır. Bu durumda ülkemizde zaten büyük bir pazara sahip olan ikinci el araç pazarının daha da büyümesine neden olmuştur. Bu durumu sayılarla ortaya koyan INDICATA raporuna göre 2020 Temmuz ayında Türkiye ikinci el çevrimiçi binek ve hafif ticari araç pazarında 238.614 adet satış gerçekleşmiştir. Bu satışlarda 2019 Temmuz ayına göre \%66, 2020 Haziran ayına göre ise \%31 oranında bir artış gözlenmiş̦tir [1]. Otomotiv Distrübütörleri Derneği (ODD) tarafından 2019 yılında yayınlanan rapora göre 2018 y1lında 641.550 olan otomobil, hafif ticari araç ve ağır ticari araç satışı 2019 yılı Ocak-Aralık döneminde \%23.3 azalarak 491.909 olmuştur [2]. Yine bu rapora göre 2019 yılı Ocak-Aralık döneminde ikinci el otomobil, hafif ticari araç ve ağır ticari araç satış1 bir önceki yıla göre \%66.4 artarak 963.584 olmuştur. Bu satışlar arasında otomobil pazarı \% 77.8 pay ve 749.700 adet ile ilk sirayı almaktadır. Otomobil pazarını $\% 17.3$ pay ve 167.023 adet ile kamyonet pazarı izlemektedir. Sayılar incelendiğinde Türkiye' de ikinci el araç satışlarının sıfır araç satışlarının iki katından fazla olduğu görülmektedir. Dünyada birçok ülkede de ikinci el araç pazarındaki satış miktarı sıfır araç pazarındaki satış sayısından büyüktür. Tüketiciler, fiyat avantajı, ilk alım vergileri, yıllık vergileri gibi nedenlerden dolayı sıfır araç yerine ikinci el araçları tercih etmektedir [3].

Gabbott tarafından yapılan bir çalışmada; tüketicilerin ikinci el araç alırken aracın yaşını, km bilgisini, fiziksel durumunu, geçmiş kullanım durumunu, fiyatını, markasını önemsediği ifade edilmiştir [4]. Duvan ve Ozturkcan tarafından yapılan bir çalışmaya göre ülkemizde ikinci el araç tercihini etkileyen en önemli faktörler; uygun fiyat, araç geçmişine ait memnuniyet, kazasızlık, boyasızlık, düşük km, iyi bir dış görünüş olarak belirtilmiştir [5]. Akçi de ikinci el araç alım sürecinde müşterilerin fiyat, yakıt tüketimi ve hasar durumu gibi faktörleri dikkate aldığını ifade etmiştir [3]. Yapılan çalışmalardan ve günlük hayattan edindiğimiz bilgilere göre özellikle ülkemizde ikinci el araç almak isteyen müşterilerin araçların geçmiş yıllarda yapılmış bakımları, kaza durumu, değişen ve boyanan kaporta parçaları gibi bilgilere önem verdiği görülmektedir.

Akçi tarafından ikinci el otomobil pazarının tüketici yönünden değerlendirilmesine ilişkin yapılan çalışmada, müşterilerin ikinci el otomobil alım aşamalarında en çok şikâyet ettikleri konu olarak satıcıların gerçek bilgileri saklaması gösterilmiştir [3]. Araştırmacı tarafından bu durumun çözümü olarak müşterilerin oto test merkezlerinden faydalanmaları tavsiye edilmiştir. Oto test merkezlerinden genel olarak aracın kaportasına ait parçaların değişme ve boyanma bilgileri alınabilmekte bunun yanında aracın motor performansı, elektronik aksamı vb. durumlar hakkında raporlara ulaşılabilmektedir. Yaşadığımız tecrübeler oto test merkezlerinin belli bir standardı olmadığı, piyasada bu işi çok basit yapan korsan firmaların olduğunu göstermektedir. Bir test merkezinde bildirilen değiş̧en bir kaporta parçasının başka bir test merkezinde değişmemiş olarak bildirildiği durumlar yaşanabilmektedir. İkinci el araç almak isteyen müşterilerin yaşadığı güven sorununun çözümü olarak bir aracın geçmişteki tüm bakım kayıtlarına, kullanılan malzeme ve parçalara, herhangi bir arıza ya da kaza kaydına, değiştirilen parçaların orijinal olup olmaması gibi bilgilere erişilmesi gerekmektedir. Bu tür bilgilere doğru bir şekilde erişebilmek için bahsedilen işlemlere ilişkin kayıtların bu işlemleri yapan servis noktaları tarafindan elektronik ortama aktarılması gerekmektedir. Mevcut durumda otomotiv firmaları garanti süresince araçların tüm bakım ve servis işlemlerinin yetkili servislerde yapılmasını zorunlu kılmaktadır. Dolayısıyla bir aracın garanti süresindeki tüm kayıtlarına erişmek mümkün olabilmektedir. Bu avantaj, bakım ve tamir işlemleri yetkili servislerde yapılan araçların ikinci el araç alımında daha fazla tercih edilmesine neden olabilmektedir. Ancak yetkili servis hizmetlerinin piyasaya göre daha pahalı olmasından dolayı araç sahiplerinin büyük çoğunluğu garanti süresi biten araçları için özel servisleri tercih etmektedir. Özel servislerin büyük çoğunluğu araç kayıtlarının elektronik ortamda yönetebileceği bir bilgi sistemine sahip olmamakla beraber; bilgi sistemi olan servislerin de diğer servislerle herhangi bir şekilde veri paylaşımı yapmadığı bilinmektedir. Araç ekspertiz merkezleri ve ikinci el araç alım 
satımına bir standart geliştirilmesi ve hizmet sunumundaki hesap verebilirlik durumunda iyileştirme yapılması adına 8 Eylül 2018 tarih ve 30529 sayılı Resmi Gazete'de yayınlanan "İkinci El Motorlu Kara Taşıtlarının Ticareti Hakkında Yönetmelikte Değişiklik Yapılmasına Dair Yönetmelik” uygulamaya alınmıştır. Bu yönetmelikle birlikte hem test merkezlerinin TSE standartlarına göre hizmet sunumu, hem de alım satım işiyle uğraşan tüccarların satış sonrası sorumlulukları düzenlenmiştir. 2018 yılı sonrası ikinci el araç alım satımlarında yönetmelik kapsamına giren araçlar için hem test merkezleri hem de satıcılar sorumluluk almakta olup, yapılan test işlemlerine dair kayıtların 5 yıl süresince saklanması zorunlu hale getirilmiştir. Ancak yönetmeliğin 3.maddesi 3.fikrasında "Sekiz yaş ve yüz altmış bin kilometre üzerindeki ikinci el otomobil ve arazi araçları için ekspertiz raporu alınması zorunlu değildir." hükmü bulunmaktadır. Dolayısı ile bu durumda birçok araç yine kanuni koruma dışına çıkmış olmaktadır [6].

Bu çalışmada bahsedilen tüm sorunların üstesinden gelebilmek için özel bir blokzinciri ağında araçların servis ve bakım bilgilerinin dağıtık ve şeffaf olarak saklanması üzerine bir çözüm önerisi sunulmuştur.

\section{MATERYAL VE METOT}

\section{A. BLOKZINCIRI}

Blokzinciri teknolojisi ilk olarak gerçekte var olup olmadığ belli olmayan Nakamoto adlı bir yazar tarafından tanıtılmıştır [7]. İlk zamanlarda kripto paralar ile bilinir hale gelen blokzinciri, sonraki yıllarda özellikleri sayesinde farklı alanlarda hayatı kolaylaştıran çözümlere öncülük etmiştir. Blokzinciri teknolojisi yapısı gereği sunduğu firsatlar ile dağıtılmış uygulamalarda devrim yaratmıştır [8]. Araştırmacılar tarafından blokzincirine ilişkin birçok tanım yapılmıştır. Bunlardan birkaçı şu şekildedir; Beck, blokzincirini bir bilgisayar ağında birçok katılımcı arasında güvenli, tutarlı ve şeffaf işlemlerin yapılmasına olanak sağlayan bir veritabanı olarak ifade etmiştir [9]. Reyna vd. blokzincirini yapılan veri işlemlerinin güvenirliğinin ağdaki paydaşlar tarafından sağlandığı bir veri yapısı olarak tanımlamıştır [10]. Zheng vd. göre blokzinciri katılımcı dügümler tarafından onaylanan işlemlerin bloklar halinde saklandığı, yeni veriler eklendikçe yeni blokların oluşturulduğu ve bu şekilde giderek büyüyen bir veri defteri olarak ifade edilmiştir [11]. Teknik açıdan bakıldığında, blokzinciri merkezi olmayan uzlaşma yöntemleri, kriptografik algoritmalar ve dağıtık, şeffaf ve değiştirilemez bir veritabanının birleşimi olarak tanımlanabilir [12]. Blokzinciri teknolojisinin avantajlarını şu şekilde stralayabiliriz:

- Dağıtık yapı: Paydaşlar merkezi bir otoriteye ya da üçüncü taraf uygulamalara güvenmek zorunda kalmaz.

- Şeffaflık: Ağda bulunan düğümler diğer düğümlerin yaptığı işlemleri görebilir.

- Otonom Çalışma: Blokzinciri ağının bir sahibi yoktur, herhangi bir düğüm zincirden çıkarsa ağ çalışmaya devam eder.

- Saldırılara karşı direnç: Proff of Work (PoW) gibi uzlaşma mekanizmaları karşı saldırı yapmak için çok fazla hesaplama gücü gerekmektedir.

- Hata izlenebilirliği: Blokzincirindeki hatalı noktalar tespit edilebilir.

- Geçmiş verilerin değişmezliği: Blokzincirinde bulunan bir verinin değiştirilmesi ya da silinmesi mümkün değildir [13].

Blokzinciri teknolojisinin sunduğu önemli hizmetlerden biri de akıllı sözleşmelerdir. Akıllı sözleşmeler, bir dizi olayın gerçekleşme şartlarını blokzinciri üzerinde yürüten bir işlem protokolüdür [14]. Akıllı sözleşmeler, taraflar arasında yapılan anlaşmaların elektronik ortamda şeffaf ve güvenli bir şekilde yürütülmesini sağlamaktadır. Birçok blokzinciri sistemi farklı yazılım dilleri desteği ile akıllı sözleşme hizmeti sunmaktadır. Örneğin Ethereum sistemi üzerinde Solidity yazılım dili ile akıllı sözleşmeler oluşturabilmek mümkündür. Akıllı sözleşmeler sayesinde farklı birçok alanda faydalı çalışmalar yapılabilmiştir. Akıllı sözleşmelerin özelliklerinden bazıları şunlardır: 
- Akıllı sözleşmeler, merkezi otoriteden bağımsız, dağıtık ve güvenli yapıları sayesinde günümüzde kullanılan klasik sözleşmelerin yerini alabileceğini vadetmektedir.

- Akıllı sözleşmeler, blokzinciri ağında çalışan makine tarafından okunabilen şeffaf ve değiştirilemez yazılım kodu parçalarıdır.

- Akıllı sözleşmeler, oluşturulduktan sonra izlenmeye gerek duymadan otomatik olarak çalışır.



Şekil 1. Blok yapısı [12].

Blokzinciri, yapılan işlemlerin boyutuna göre artan, birbirine bağlı bloklardan oluşmaktadır. Bir blok Şekil 1'de gösterildiği gibi önceki bloğa ait değerler, zaman damgası, blok versiyonu ve işlem sayac1 gibi bilgileri bulundurmaktadır. Blokların birbirine bağlanmasıyla Şekil 2'deki gösterilen blokzinciri yapısına benzer bir zincir oluşur.

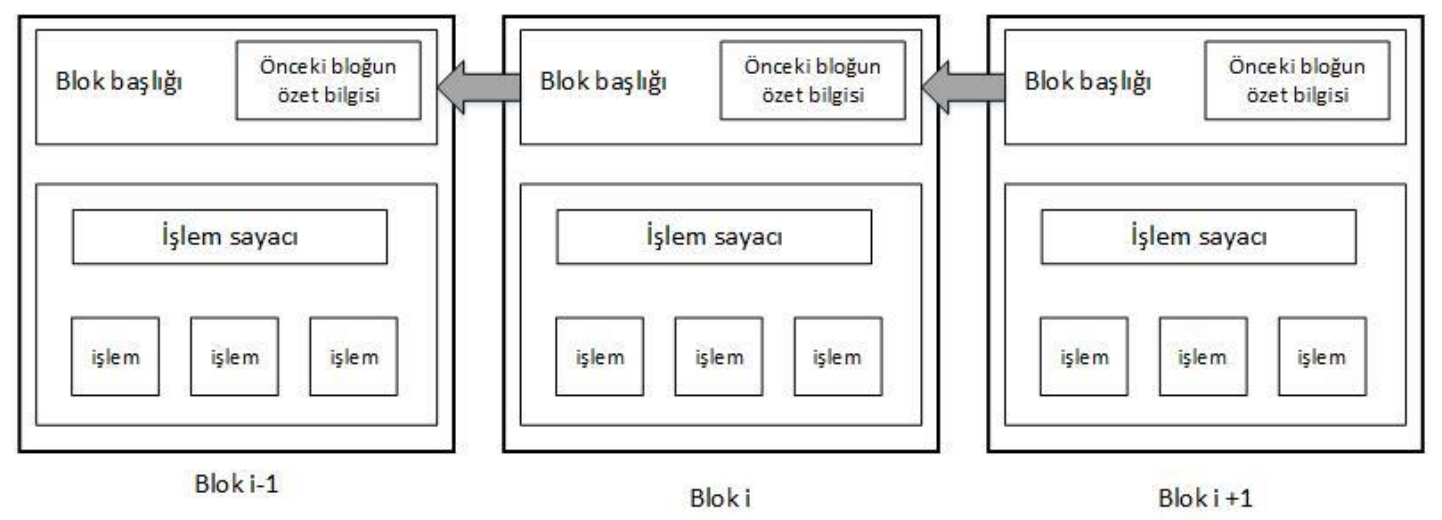

Şekil 2. Blokzinciri yapısı [12].

Mevcut blokzinciri sistemleri Genel (Public) Blokzinciri, Özel (Private) Blokzinciri ve Konsorsiyum (Consortium) Blokzinciri olmak üzere üç kategoride sınıflandırılmıştır [15,16]. Genel Blokzinciri, çeşitli kurumlara bağlı ya da bağımsız kişilerin katılımına, kayıt eklemesine ve madencilik yapmasına imkân veren açık bir platform sunmaktadır. Bu tür blokzincirlerinde herhangi bir kısıtlama yoktur ve bu yüzden izinsiz blokzinciri olarak da adlandırılır. Katılımcılar arasında izinleri doğrultusunda veri paylaşımı ve alışverişine olanak sağlayan bir ya da birden fazla grup tarafindan yönetilen blokzinciri yapıları Özel Blokzinciri olarak ifade edilmektedir. Ağa bir paydaşın katılımı ve erişimi, ağı yöneten grup tarafından belirlenen kurallara göre yapılmaktadır. Konsorsiyum Blokzinciri, blok doğrulama ve uzlaşma işlemlerinde tek bir organizasyonun yerine önceden belirlenmiş bir grup paydaşın karar verici olarak yer aldığ 1 kısmen özel ve izinli bir blokzinciri olarak tanımlanabilir. Bu tür ağlarda kimlerin katılımcı olacağına ve kimlerin madencilik yapabileceğine bu paydaşlar tarafından yönetilmektedir. $\mathrm{Bu}$ çalışmada özel blokzinciri üzerinde bir uygulama önerilmiştir. 


\section{B. MOTORLU ARAÇLAR İÇIN MEVCUT BLOKZINCİRI UYGULAMALARI}

Son yıllarda blokzinciri teknolojisi çeşitli uluslararası kuruluşlar, özel sektör ve basın tarafından büyük ilgi görmektedir. Aynı şekilde birkaç yıl önce alanyazında blokzinciri konulu çalışma sayısı sınırlı iken günümüzde bu teknoloji ile ilgili farklı alanlarda yapılmış birçok çalışma bulunmaktadır [17]. Alanyazın incelendiğinde motorlu araçlar üzerine yapılmış blokzinciri tabanlı çalışmalara rastlamak mümkündür. Bunlar genelde motorlu taşıtların vergi, muayene, sahiplik gibi bilgilerinin dağıtık olarak saklanması, araç kiralama, elektrikli araçların kripto paralar karşılı̆̆ şarj edilmesi gibi konular üzerinedir. Bu çalışmalardan bazılarına aşağıda yer verilmiştir.

Danimarka'da hayata geçirilen Vehiche Wallet adlı proje ile her aracın üretim, bakım, sahiplik durumu, kiralama ve hurdaya çıkma gibi bilgilerin araçlar için blokzinciri ağı üzerinde oluşturulan dijital cüzdanlarda saklanabilmiştir. Bu proje sayesinde Danimarka vergi kurumları araç bilgilerine erişebilmiş ve vergi tahsilatlarında kolaylık sağlanmıştır [18-19]. Araç kiralama hizmetlerinde hem firma hem de müşterilerin mağdur olduğu durumlar ile karşılaşılabilmektedir. Hassija vd. sundukları çalışmada araç kiralama hizmetlerinde blokzinciri ve akıllı sözleşmelerden faydalanarak, kabahatli ve ceza gibi durumların dijital olarak yönetilmesi sağlanmıştır [20].

Son yıllarda elektrik ile çalışan araçlar günlük hayatta kullanılmaya başlanmıştır. Yakın gelecekte de bu araçların yaygınlaşması öngörülmektedir. Kim vd. elektrikli araçların şarj istasyonlarında şarj edilmesi, ücretinin de blokzinciri üzerinden ödenmesini öneren bir çalışma yapmıştır [21]. Pustisek vd. elektrik şarj istasyonlarının yaygınlaşacağını belirtmiş ve araç sahipleri için trafik, zaman ve maliyet gibi etkenleri göz önünde bulundurarak en avantajlı şarj istasyonunun belirlenmesi üzerine bir çalışma yapmıştır [22]. Xia vd. ise elektrikli araçların birbiri ile elektrik transferi yapabilmesi ve yapılan transfer karşıllı̆̆ında ücret ödenmesi üzerine bir sistem önermişlerdir [23].

Kim vd. giderek yaygınlaşan otomatik sürüş özellikli akıllı araçların daha güvenli yolculuk için kendi aralarında veri alışverişi yapabileceklerine ilişkin bir çalışma yapmıştır [24]. Yazarlar çalışma sayesinde diğer araçların durumu, yol çalışmaları ve diğer çevre bilgilerinin blokzinciri üzerinde tutulması ve araçlar arasında paylaşılması sayesinde daha güvenli otomatik sürüş imkanı sağlanabileceğini ifade etmiştir. Çalışmada bir kaza, acil durum veya suç teşkil eden bir durumun tespit edilmesi durumunda akıllı sözleşmeler ile bu durumun kayıt altına alınması ve ilgili birimlerle paylaşılmasının faydalı olacağından bahsedilmiştir.

Hossain vd. kamyonet, otomobil ve motosiklet gibi motorlu araçlara ilişkin araç sahibi bilgileri, aracın maddi değeri, aracın rengi, araca ait vergi ve sigorta bilgileri gibi verilerin blokzinciri üzerinde saklanmasına ilişkin bir çalışma yapmışlardır [25]. Yazarlar bu çalışma sayesinde geleneksel sistemlerde gerekli olan resmi belge zorunluluğunun ortadan kalkabileceği ve belge doğrulama işlemlerinin daha hızlı, şeffaf ve güvenilir olabileceğini belirtmiştir. Ama çalışma incelendiğinde her araç sahibinin blokzincirinin bir nodu (katılımcısı) olduğu görülmüştür. Bunun uygulamanın hataya geçirilmesi durumunda çok fazla her katılımcı için çok büyük veri alanı gerektireceği ve performans sorunlarına neden olabileceği düşünülmektedir.

Demir vd. motorlu araçların sigorta kayıtlarının blokzinciri üzerinde saklanması ve paylaşılması üzerine bir çalışma yapmıştır [26]. Bu çalışmanın amacı araç sahipleri, sigorta firmaları, üreticiler, adli birimler ve güvenlik birimleri gibi paydaşlar için güvenli verinin sağlanması olarak belirtilmiştir. Aracın sahiplik bilgileri, sigorta durumu, sürücü belgesi vergi ödemeleri gibi verilerin paydaşlar arasında güvenli bir şekilde paylaşılması durumunda daha güvenilir ve daha hızlı işlem yapmanın mümkün olacağı iddia edilmiştir. Örnek olarak ise polis kontrol noktasında bir araç ve sürücü için gerekli kontrol işlemlerinin önerilen sistem sayesinde çok daha hızlı ve güvenilir olabileceği ifade edilmiştir.

Literatürde benzer çalışmaların giderek arttığı görülmektedir. Birkaç istisna dışında yapılan çalışmaların teorik olduğu ve ileride geliştirilmek üzere çözüm önerileri içerdiği görülmüştür. Blokzinciri teknolojisinin gelişmesi ve yaygınlaşmasıyla beraber yakın zamanda günlük hayatta uygulamalı çalışmalara rastlamanın mümkün olacağı düşünülmektedir. Diğer ülkeler yapılan çalışmalarda daha çok 
motorlu araçlara ait vergi ödemeleri, sigorta durumu, aracın sahipliği gibi veriler üzerinde durulmuştur. Diğer ülkelerden farklı olarak ülkemizde motorlu araçların bir yatırım aracı olarak görüldüğü ve ikinci el araç alım satımının çok fazla olduğu bilinmektedir. Yine diğer ülkelerden farklı olarak ikinci el araç alım satımlarında aracın kaporta durumu ve servis kayıtları gibi bilgilerine önem verildiği ve bu bilgilerin aracın değeri üzerinde etkili olduğu görülmektedir. Bu çalışmada diğer çalışmalardan farklı olarak araçların kaporta durumu, servis kayıtları ve kullanılan malzeme ve parça bilgilerinin blokzinciri üzerinde yönetilmesi ve paylaşılması üzerine bir çözüm önerisi getirilmiştir.

\section{ARAÇ CÜZDANI UYGULAMASI}

$\mathrm{Bu}$ çalışmada motorlu araçların servis ve bakım bilgilerinin dağıtık ve şeffaf olarak blokzinciri ağ 1 üzerinde saklanması üzerine bir uygulama önerilmektedir. Aşağıdaki bölümlerde bu uygulamanın teknik özellikleri, örnek ekran tasarımları (mockup) ve günlük hayatta nasıl uygulanabileceği hakkında bilgi verilmektedir.

Tablo 1. Uygulamadaki aktörlerin görev ve hakları.

\begin{tabular}{|c|c|}
\hline Aktör & Görevleri ve Hakları \\
\hline Uygulama yönetimi & $\begin{array}{l}\text { Uygun blokzinciri ağının kurulması } \\
\text { Blokzinciri ağı için gerekli bakım güncellemelerin } \\
\text { yapılması } \\
\text { Katılımcı özel servislerin belirlenmesi ve yönetimi } \\
\text { Özel servislere kurulum sırasında ve sonrasında maddi } \\
\text { ve teknik destek verilmesi } \\
\text { Mobil uygulama geliştirilmesi ve yönetilmesi } \\
\text { İdari ve mali işlerin yönetilmesi } \\
\text { Tanıtım, reklam ve iletişim merkezi gibi hizmetlerinin } \\
\text { yerine getirilmesi }\end{array}$ \\
\hline Özel servis & $\begin{array}{l}\text { İlk kurulum için uygulama yönetimiyle birlikte } \\
\text { çalış1lması } \\
\text { Kurulan uygulama noktasının bakım ve güvenliğinin } \\
\text { sağlanması } \\
\text { Araç bilgilerinin doğru ve düzenli olarak uygulamaya } \\
\text { girilmesi } \\
\text { Araç bilgisi sorgulamak isteyen müşteriler için ücret } \\
\text { karş1lığ1 rapor oluşturulması } \\
\text { İdari ve mali konularda uygulama yönetimi ile } \\
\text { çalışılması }\end{array}$ \\
\hline Araç sahibi & $\begin{array}{l}\text { Kendi aracına ait bilgilerin blokzincirinde saklanmasını } \\
\text { talep edebilir. } \\
\text { İstediğinde özel servisler veya mobil uygulama } \\
\text { aracılığıyla kendi aracına ait bilgileri sorgulayabilir. }\end{array}$ \\
\hline İkinci el araç müşterisi & $\begin{array}{l}\text { Almak istediği araca ait bilgileri özel servis veya mobil } \\
\text { uygulama aracılı̆̆ıyla makul bir ücret karşıllığında } \\
\text { sorgulayabilir. }\end{array}$ \\
\hline Parça sağlayıcı & $\begin{array}{l}\text { Uygulama üzerinden özel servislere parça ve malzeme } \\
\text { bilgisi sunarak, kullanılan parça ve malzemelerin kayıt } \\
\text { altına alınmasını sağlar. } \\
\text { Kayıtlarını şeffaf ve doğru bir şekilde paylaşan bu } \\
\text { firmalar sigorta şirketleri ve müşteriler tarafından tercih } \\
\text { edilecektir. }\end{array}$ \\
\hline
\end{tabular}


Önerilen araç cüzdanı uygulamasında iki grup bulunmaktadır. Bunlardan birincisi araç verilerini blokzinciri ağına yükleyecek özel araç servisleri, ikincisi ise blokzinciri üzerinde saklanan araç verilerini sorgulamak isteyen ikinci el araç müşterileridir. Bu blokzinciri ağına sadece yetkilendirilmiş özel servislerin veri kaydedebilmesi gerekmektedir. Bu nedenle önerilen araç cüzdanı uygulaması özel bir blokzinciri üzerinde çalışmalıdır. Uygulama kapsamında öncelikle özel bir blokzinciri ağının kurulması gerekmektedir. Bunun için HyperLedger [27], Ethereum [15], MultiChain [28] gibi blokzinciri sistemleri kullanılabilir. Piyasada ve akademik çalışmalarda bu sistemlerin başarılı uygulama örneklerine rastlamak mümkündür. Özel servislere gerekli teknik destek sağlanarak bu servis noktalarının kurulan blokzinciri ağının birer nodu (katılımcısı) olması sağlanmalıdır. Katılımcı özel servisler bir araca ilişkin yapılan her bakım ve servis işleminin blokzincirine kaydedilmesini sağlamalıdır. Burada her aracın blokzinciri ağında bir cüzdan hesabı olmalıdır. Özel servisler tarafından kayıtlı olmayan araçlar için blokzincirinde cüzdan oluşturma işlemi de yapılabilmelidir. Bu cüzdan oluşturma aşamasında her araç için kimlik numarası yerine geçen motor şasi numarasının kullanılması uygun olacaktır.

Uygulamada ikinci el araç almak isteyen müşterilerin sorgulama yapabilmesi sağlanmalıdır. Bunun için uygulamaya katılımcı özel servislerin bilgi girişinin yanında araç bilgilerini sorgulama hizmeti de vermesi gerekmektedir. Böylelikle kayıtlı herhangi bir servisin girdiği araç bilgisine diğer özel servisler tarafından erişmek mümkün olacaktır. Ayrıca blokzinciri sistemleri tarafindan sağlanan API (Uygulama Arayüzü) hizmetleri aracıllğıyla geliştirilecek bir mobil uygulama sayesinde müşterilerin özel bir servise gitmesine gerek kalmadan araç sorgulama imkânı verilebilir. Uygulamada kurulan blokzinciri türü özel blokzinciri olduğu için ağa katılmak isteyen özel servislerin belirlenmesi ve yönetilmesi gerekmektedir. $\mathrm{Bu}$ yönetim görevi bir firma veya bir organizasyon tarafından yürütülebileceği gibi özel servisler tarafından belirlenen bir kurul da bu görevi yerine getirebilir. Önerilen uygulamanın doğru bir şekilde kurulması ve yönetilmesi için uygulamada yer alan aktörlerin görevleri ve hakları Tablo 1' de verilmiştir.

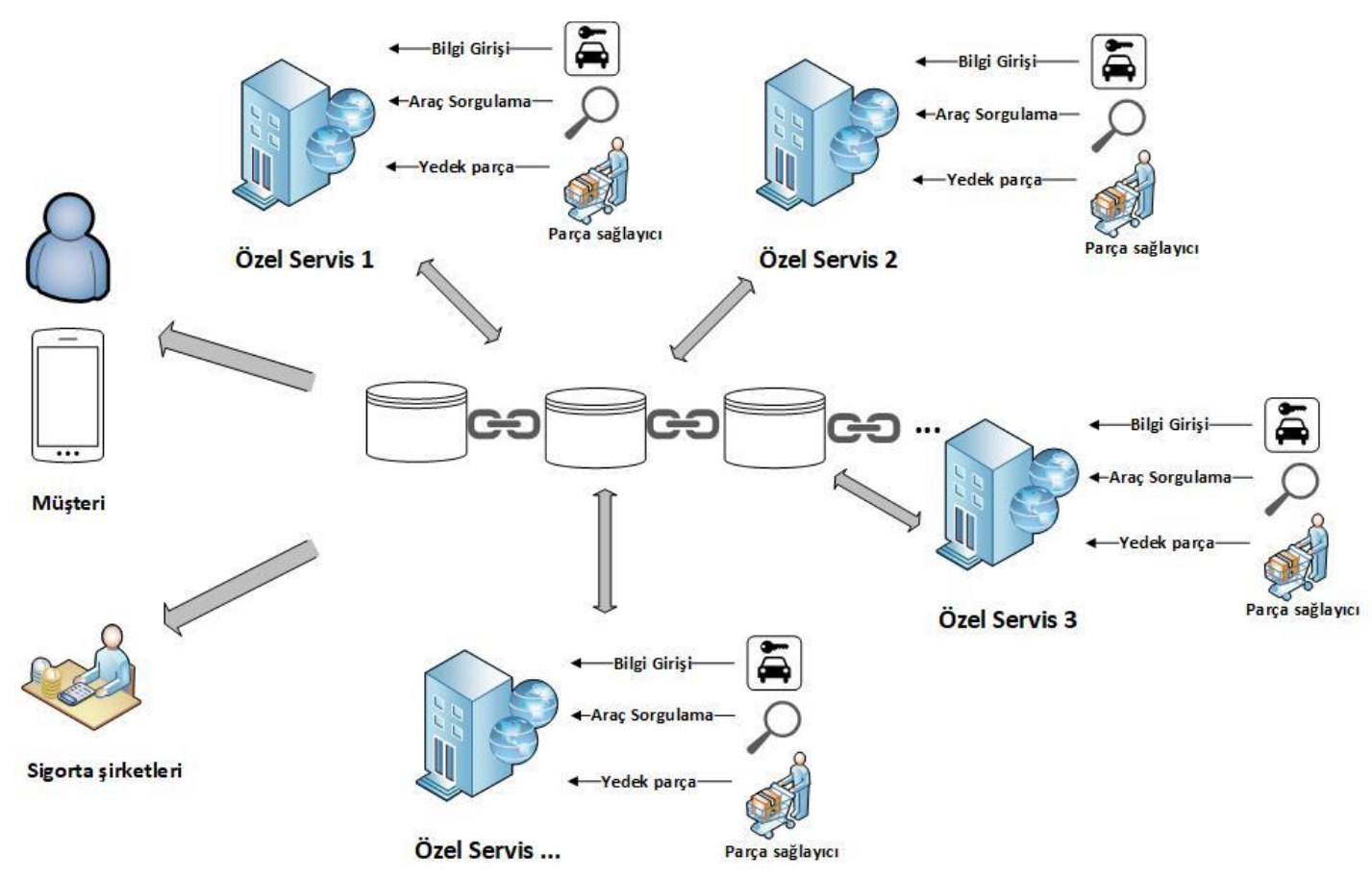

Şekil 3. Araç cüzdanı uygulamasının genel yapısı.

Şekil 3'te önerilen araç cüzdanı uygulamasının genel yapısı verilmiştir. Şekilde görüldüğü gibi uygulamaya katılan özel servisler blokzinciri ağında birer paydaş olarak yer almaktadır. Bu paydaş özel 
servisler ağa katıldıktan sonra güncel bir şekilde bütün araçların cüzdanlarına başka bir deyişle servis ve bakım bilgilerine erişebilmekte ve veri merkezi olarak çalışmaktadır. Özel servisler kullanacağı parçaları bilgilerini de uygulamaya veri sağlayan parça sağlayıcı firmalar tarafindan temin etmesi durumunda kullanılan parçaların da blokzinciri üzerinde takip edilmesi mümkün olacaktır. Bu sayede hem müşteri kullanılan parçanın özelliklerini görebilecek hem de sigorta şirketleri ödeme süreçlerini daha doğru ve şeffaf yapabilecektir. Sigorta şirketleri, araç sahipleri ve araç servisleri anlaşmalı olarak daha fazla ödeme almak için usulsüz olarak yüksek masraf çıkardığı durumlar ile karşılaşılmaktadır. Bu uygulama sayesinde parçaların ve malzemelerin şeffaf bir şekilde uygulama üzerinden takip edilebilmesi sayesinde bu tür usulsüzlüklerin önüne geçilebilecektir. Şekilde görüldüğü gibi geliştirilen mobil uygulama üzerinden de istenilen bir araca ait bilgilere blokzinciri ağı üzerinden anlık olarak erişmek mümkün olacaktır.



Şekil 4. Araç Cüzdanı Uygulamasının ana menüsü ve bilgi girişi ekranları.

Önerilen sistemin daha iyi anlaşılması için örnek ekran tasarımları hazırlanmıştır. Şekil 4'te araç cüzdanı uygulamasının ana menüsü ve bilgi girişi ekranları yer almaktadır. Özel servisler, ana menü ekranında görülen menülerden araç tanımlayabilecek, bilgi girişi yapabilecek, ücret tahsil edebilecek ve uygulama ayarları ve disk durumu gibi bilgilere erişebilecektir. 


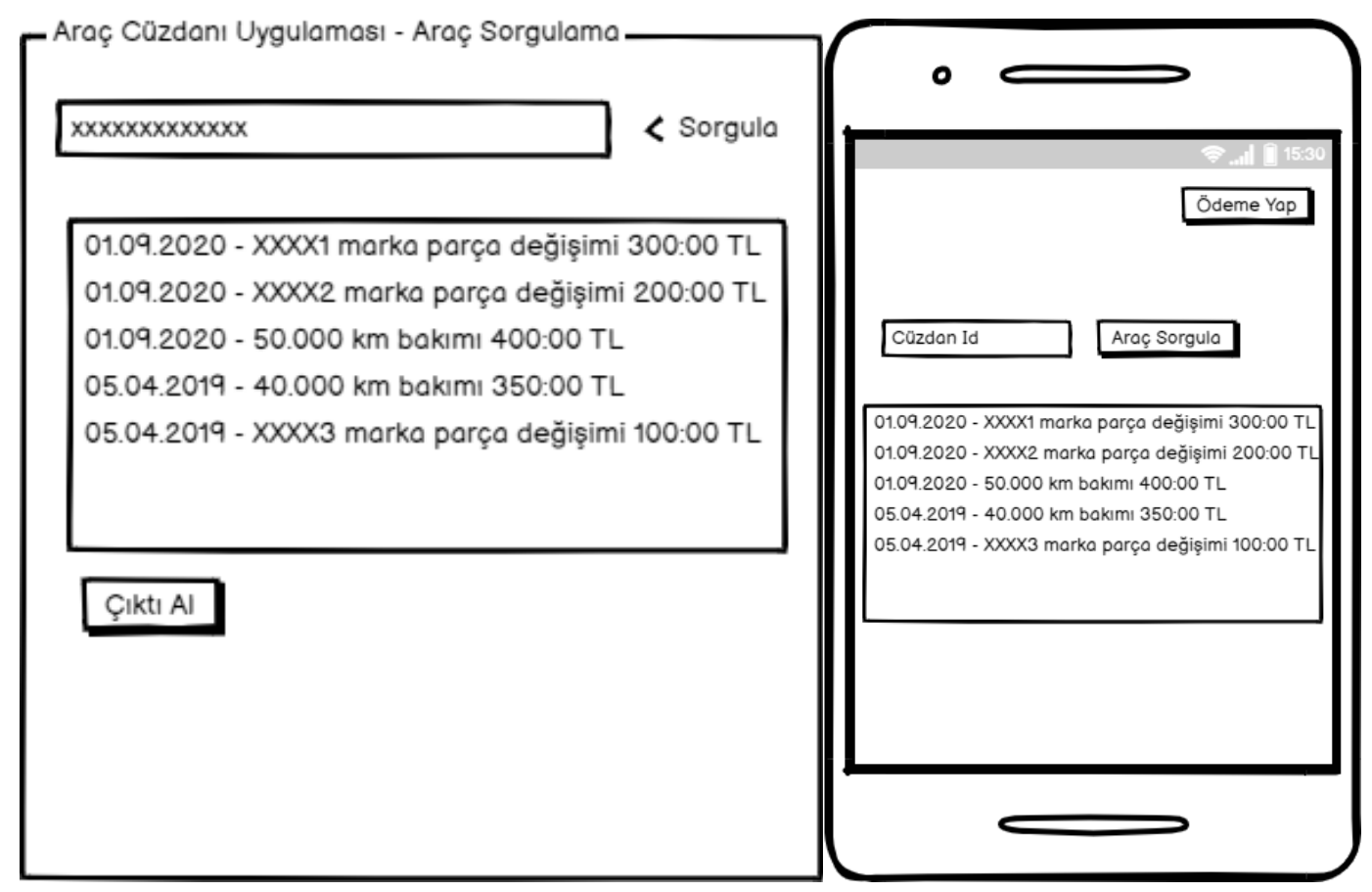

Şekil 5. Özel servis uygulaması ve mobil uygulamada bulunan araç sorgulama ekranları.

Şekil 5' te özel servisler tarafından kullanılan uygulama ve müşteriler tarafından kullanılan mobil uygulama üzerinden yapılan araç sorgulama ekranları görülmektedir. $\mathrm{Bu}$ ekranlarda sorgulanmak istenilen aracın cüzdan ID değeri girilerek o aracın blokzinciri üzerindeki tüm kayıtlarına erişmek mümkün olmaktadır. Bununla birlikte, cüzdan ID sadece araç sahibi ve servis yetkilisi tarafindan bilindiği için, araç bilgilerin üçüncü kişiler tarafından istemsiz görüntülenmesi engellenmiş olur. Ekran tasarımlarında görüldügü gibi özel servis uygulamasında çıktı alma seçeneği, mobil uygulamada ise ödeme yapma seçeneği bulunmaktadır. Mobil uygulama ve özel servisler üzerinden yapılacak araç sorgulama ödemelerinin kredi kartı veya nakit olarak tahsil edilmesi önerilmektedir. İlerleyen zamanlarda bu seçeneklere alternatif olarak özel blokzinciri ağı üzerinde yönetilen sanal paralar ile de ödeme seçeneği sunulması planlanabilir.

\section{D. ÖNERILEN UYGULAMANIN GELIŞTIRIILMESI}

Literatürde blokzinciri konulu birçok çalışmaya rastlamak mümkündür. Bunlardan büyük kısmı mimari ve çözüm önerileri içeren çalışmalardır. Sayısı çok az olan bazı çalışmalarda ise mevcut blokzinciri sistemleri kullanılarak gerçek zamanlı uygulamalar sunulmuştur. Abadi vd. 2018 yılı itibariyle bu çalışmalarda kullanılan blokzinciri sistemlerini şekil 6'daki gibi listelemiştir.

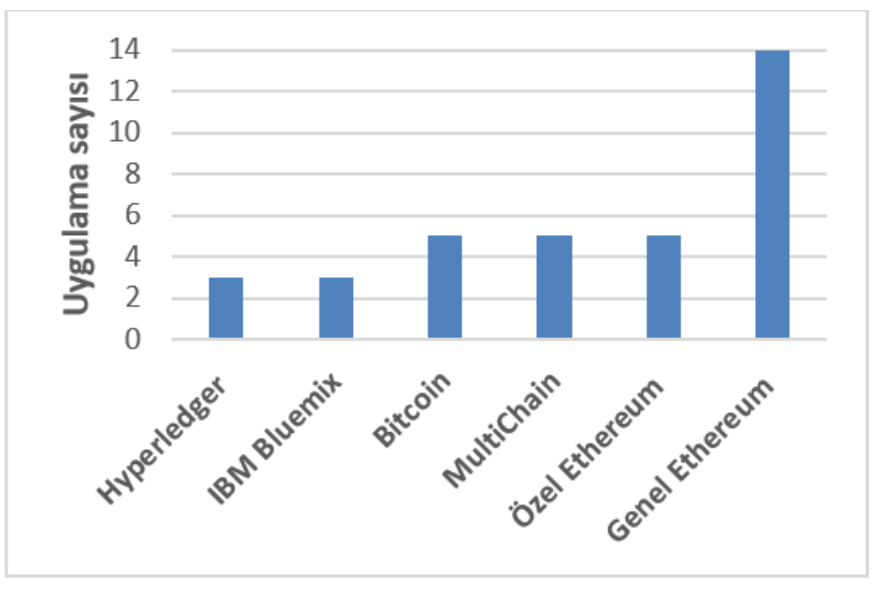


Şekil 6. Literatürde kullanılan blokzinciri sistemleri [29].

Abadi vd. tarafından yapılan çalışmaya göre araştırmacılar blokzinciri sistemi olarak en çok Ethereum, Bitcoin, MultiChain, Hyperledger ve IBM Bluemix sistemlerini tercih etmiştir. Genel olarak incelendiğinde bu sistemler benzer özellikler ve benzer performans değerlerine sahiptir. Bu çalışmada önerilen uygulama için blokzinciri sistemi olarak kullanımı kolaylığı ve birçok yazılım dili için API desteği sunan MultiChain sistemi tercih edilmiştir. Tekrar vurgulamak gerekirse blokzinciri sistemleri genel olarak benzer özellikler sunmaktadır, bu nedenle araştırmacılar tarafından yazılım dili ya da önceki tecrübeler 1şığında farklı blokzinciri sistemleri de tercih edilebilir.



Şekil 7. Blokzinciri kurulumu.

Blokzinciri kurulumu için Windows 10 işletim sistemi yüklenmiş Intel Xeon $2.40 \mathrm{GHz}$ işlemci ve 32 GB belleğe sahip bir bilgisayar kullanılmıştır. İlk aşamada bu bilgisayara MultiChain sistemi kurulumu gerçekleştirilmiştir. Şekil 7'de kuruluma ilişkin ekran görüntüsü verilmiştir. Bu ekranda da görüldüğü gibi "arac_cuzdani” adlı zincir kurulmuş ve gerekli dosyalar oluşturulmuştur. Kurulum yapılan bilgisayarın ip adresi 192.168.56.1 olarak belirlenmiş ve kurulan "arac_cuzdani” adlı zincire bağlanmak için “arac_cuzdani@192.168.56.1” bilgisi herkese açık olarak yayınlanmıştır. 


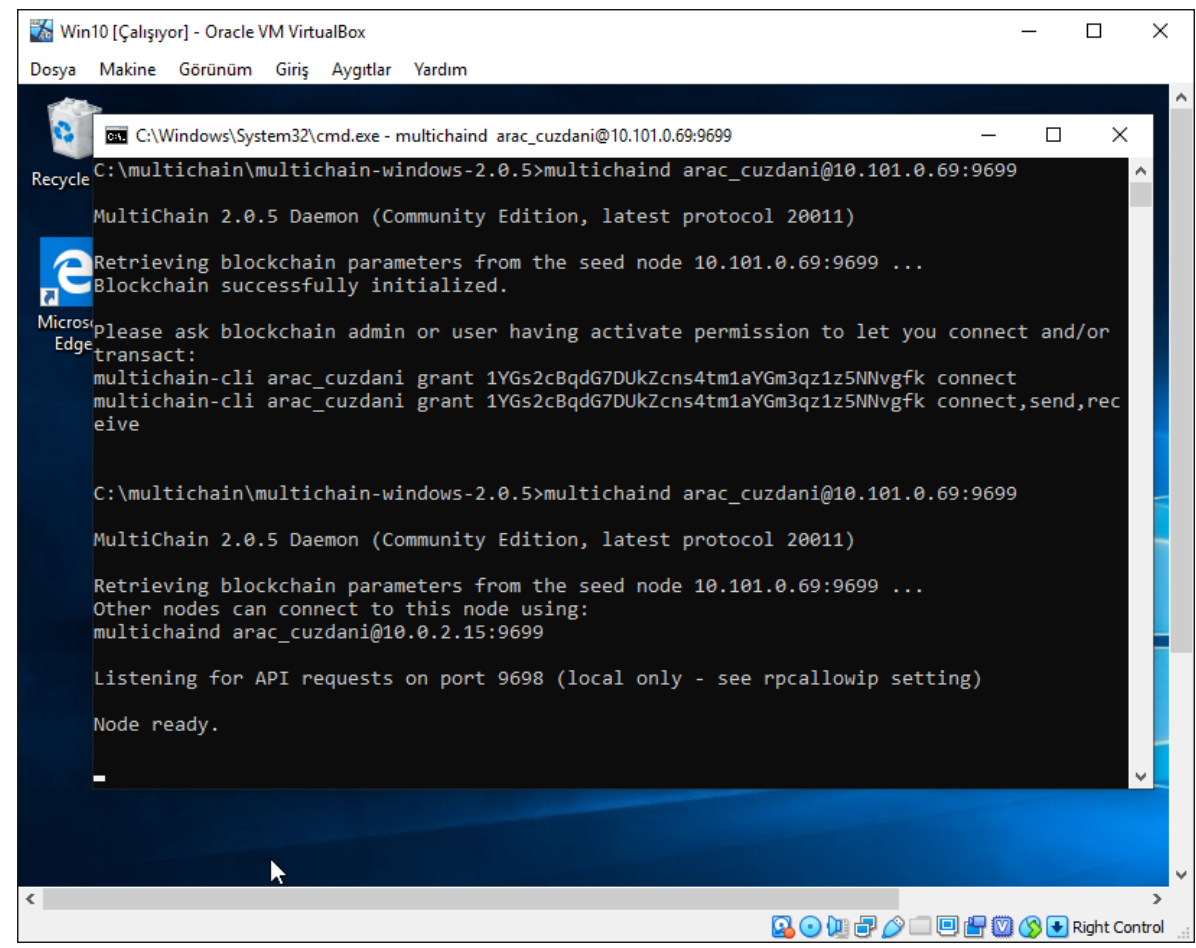

Şekil 8. Blokzincirine katılım.

Multichain ve diğer özel blokzinciri sistemlerinde zincire katılımcı eklenmesi için ip adresi ve port numaralarına göre firewall üzerinden gerekli izinlerin sağlanması gerekmektedir. Bu çalıșmada üzerinde geliştirme yapılan bilgisayara Oracle VM VirtualBox programı kurularak bir sanal makine oluşturulmuş ve internet bağlantısı sağlanmıştır. Daha sonra bu sanal makineye gerekli MultiChain dosyaları yüklendikten sonra herkese açık olarak yayınlanan “arac_cuzdani@192.168.56.1” komutu MultiChain komutu olarak çalıştırılmıştır. Şekil 8'de MultiChain komutunun çalışmasına ilişkin ekran görüntüsü görülmektedir. Sanal makine üzerinden ilgili komut girildikten sonra özel blokzinciri olan “arac_cuzdani” zincirine bağlanmak için izinlerin verilmesi gerekmektedir. İlgili izinler ve tanımlamalar yapıld̄ktan sonra sanal makine üzerinden kurulan zincire bağlantı sağlanabilmektedir.

MultiChain tarafından geliştiricilere sunulan en önemli araçlardan biri de "MultiChain Explorer" adlı web uygulamasıdır. Bu uygulama sayesinde web üzerinden blokzinciri üzerindeki tüm faaliyetler eş zamanlı olarak tarayıcı üzerinden yönetilebilmektedir. Bu geliştirme aşamasında da "MultiChain Explorer" uygulamasından faydalanılmıştır.

Şekil 9'da "MultiChain Explorer" adlı uygulamanın ekran görüntüsüne yer verilmiştir. Şekilde görüldüğ̈̈ gibi 192.168.56.1 ip adresi üzerinde kurulan "arac cuzdani” adli zincire 10.101.0.69 ip adresine sahip bilgisayar katılımcı olarak bağlanabilmiştir. Bu uygulama sayesinde çok sayıda katılımcının bilgileri ve izinleri yönetilebilir. 
MultiChain - Araç Cüzdanı $\times$

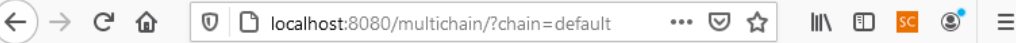

Multichain - Araç Cüzdanı - arac_cuzdani

Node Permissions Issue Asset | Update Send Create Offer |Accept Create Stream

Publish View Streams Filters: Transaction |Stream

My Node

\begin{tabular}{|l|l|}
\hline Name & arac_cuzdani \\
\hline Version & 2.0 .5 \\
\hline Protocol & 20011 \\
\hline $\begin{array}{l}\text { Node } \\
\text { address }\end{array}$ & arac_cuzdani@192.168.56.1:9699 \\
\hline Blocks & 59 \\
\hline Peers & 1 \\
\hline
\end{tabular}

Connected Nodes

\begin{tabular}{|l|l|}
\hline Node IP address & 10.101 .0 .69 \\
\hline Handshake address & $\begin{array}{l}\text { 1YGs2CBqdG7DUkZcns4tm } \\
\text { 1aYGm3qZ125NNvgfk }\end{array}$ \\
\hline Latency & $0.070 \mathrm{sec}$
\end{tabular}

Latency $0.070 \mathrm{sec}$
My Addresses

\begin{tabular}{|l|l|}
\hline Label & Set label \\
\hline Address & $\begin{array}{l}\text { 1Tr8BvQBXehbYsfvccfC5xMETjRRqxcts } \\
\text { N8a5X }\end{array}$ \\
\hline Permissions & $\begin{array}{l}\text { connect, send, receive, issue, } \\
\text { create, mine, admin, activate - } \\
\text { change }\end{array}$ \\
\hline
\end{tabular}

\section{Get new address}

Şekil 9. MultiChain Explorer uygulaması katılımeı ekranı.

Multichain - Arạc Cüzdanı $\times$

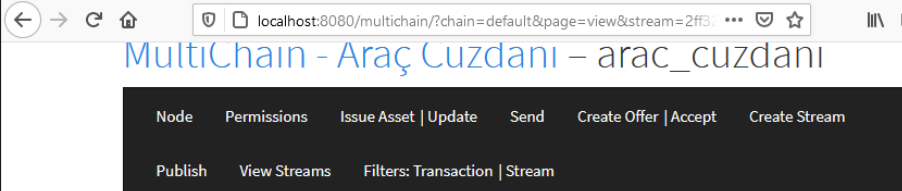

Subscribed streams

Name root

Created 17 reBvQBXehbrsfuccfes

by XMETjRRqxctsN8a5X

Items 0

Publishers

Name Araclar

Created 1Tr8BvQBXehbysfuccfes

by XMETjRRquctsN8a5X

Items 0

Publishers

Name Servisler

Created 1Tr8BvQBXehbysfuccfes

by $\quad$ MEETRRqxCtsN8a5X

Items 0

Publishers

Name Parcalar

Created 1 Tr8BvQBXehbYsfuccfos

by $\quad$ XMETjRRqxctsN8a5:

Items
Stream: Parcalar - 2 of 2 items

Publishers Tr8BvQBXehbYsfvCCFC5XMETjRRgxctsN8a5X

Key(s)

JSON

data

")

"boya":

"1d": "xxxxxxxx"

"id": "xxxxxxx",

"tip": "tavan",

nfiyat": " 3000

Added 2020-11-2421:06:11 GMT (confirmed)

Publishers Tr8BvQBXehbYsfvCCFC5xMETjRRaxctsN8a5X

Key(s)

JSON



gervis_id": "xxxxxxxxxxxx",

"parcalar": i

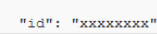

Şekil 10. MultiChain Explorer uygulamasında data akışları. 
MultiChain sunduğu data stream(veri akışı) özelliği sayesinde klasik veritabanı tablolarına benzer yapıda veri saklamayı sağlamaktadır. Data stream üzerinde metin, json verisi, dosya gibi farklı yapılarda veri saklanabilmektedir. Şekil 10'da "MultiChain Explorer" uygulaması aracılığıyla tanımlanmış data akışları görülmektedir. Şekil incelendiğinde "Parcalar" adlı data akışında arac_id, servis_id ve parçaların id, fiyat gibi özellikleri ile saklanabildiği görülmektedir. Data akışlarına kaydedilecek verinin formatı istenildiğinde ihtiyaca göre güncellenebilir. Data akışlarının bir diğer özelliği ise her katılımcı için data akışlarına okuma ve yazma izinlerinin ayrı ayrı tanımlanabilmesidir. Bu sayede "Parcalar" adlı data akışı için tüm servislere yazma izni verilirken, "Servisler" adlı data akışı için sadece yönetim birimine yazma izni verilebilmiştir.

Bu bölümde MultiChain sistemi kullanılarak bir zincir oluşturulmuş ve bu zincire başka bir bilgisayarın da katılımcı olarak bağlanması sağlanmıştır. Zincir üzerinde oluşturulan "Araclar", "Servisler" ve "Parcalar" adlı data akışları sayesinde verilerin dağıtık ve değiştirilemez olarak kaydedilmesi sağlanmıştır. Buraya kadar bir blokzinciri sistemi kurulumu ve yönetimi hakkında ayrıntılı bilgi verilmiştir. Bu aşamadan sonra sektörün ihtiyaçlarının ayrıntılı analizinin yapılması ve MultiChain tarafından PHP, C\#, Pyhton, Java, Javascript gibi yazılım dilleri için sunulan API'ler sayesinde geliştirmeye devam edilmesi gerekmektedir.

\section{E. ÖNERILEN UYGULAMANIN HAYATA GEÇİRILMESİ}

Önerilen uygulamanın ilk kurulumu, devamının sağlanması ve yönetilmesi sırasında bazı zorluklarla karşılaşılması öngörülmektedir. Günümüzde birçok veri elektronik ortamda saklanmakta ve yönetilmektedir. Dünyada ve ülkemizde verilerin şeffaflığı ve güvenliği giderek daha önemli hale gelmektedir. Bu kapsamda önerilen araç cüzdanı uygulamasının ülkemizde de son yıllarda artan dijitalleşme çalışmalarına katkıda bulunacağı düşünülmektedir. Araç cüzdanı uygulamasının sağlıklı bir şekilde hayata geçirilmesi ve yaygınlaşması için kamu destekli araştırma birimlerinden destek alınması ve yasal mevzuat açısından gerekli çalışmaların yapılması çok önemlidir. Uygulamanın yaygınlaşması sonrasında elde edilen veri havuzu, veri madenciliği, makine öğrenmesi, büyük veri gibi teknolojilerin kullanımı sayesinde faydalı birçok çalışmada kullanılabilir. Ayrıca elde edilen verilerin E-devlet, Emniyet Genel Müdürlüğü, TÜVTÜRK Araç Muayene İstasyonları ve bankalar gibi kurum ve kuruluşlar ile paylaşılması günlük hayatı kolaylaştırabilir.

Uygulamanın başarısı için özel servislerin katılımı ve bu servislerin sağlıklı bir şekilde uygulamayı kullanması çok önemlidir. Bunun için de özel servislere teknik destek verilmesi gerekmektedir. Örneğin Şekil 11'de ülke çapında bazı yetkili servislerde bulunan egzoz emisyon ölçüm cihazının bir örneği bulunmaktadır. Araç cüzdanı uygulamasına katılan özel servisler için de bu cihaza benzer bir cihaz tasarlanması özel servislerin işini kolaylaştıracaktır. Uygulama için gerekli monitör, sunucu, disk üniteleri, yazıcı gibi donanımların bu cihaz üzerinde yer alması sağlanabilir.

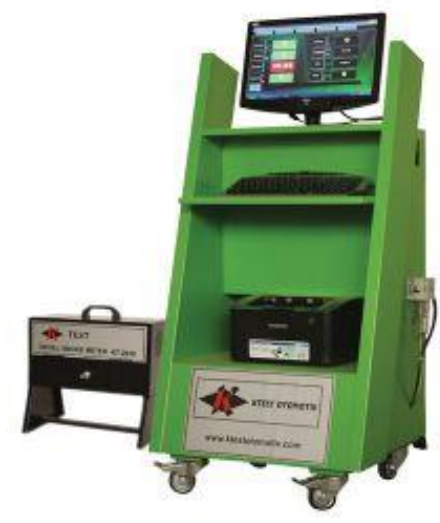

Şekil 11. Egzoz emisyon ölçüm cihazı [30]. 
Gerekli tanıtım ve pazarlama çalışmalarından sonra ikinci el araç müşterilerinin güvenli ve şeffaf olarak araç kayıtlarına erişebildiği için araç cüzdanı olan araçları tercih etmesi öngörülmektedir. Aynı zamanda, ileride kendi aracını satarken kolaylık sağlayacağını düşünen araç sahiplerinin de bakım ve servis işleri için araç cüzdanı uygulamasına dâhil olmuş özel servisleri tercih edeceği düşünülmektedir. Aynı şekilde uygulamaya veri sağlayan parça sağlayıcılarından temin edilen parçaların şeffaf ve değiştirilemez olarak izlenebilmesi özel servisler, sigorta şirketleri ve araç sahipleri için önemli olacaktır. Verilerin şeffaf, güvenli, dağıtık ve değiştirilemez bir şekilde paylaşılmasına olanak sağlayan araç cüzdanı uygulamasının araç sahipleri, müşteriler, özel servisler ve sigorta şirketleri tarafından tercih edileceği ve bu sayede uygulamanın yaygınlaşacağ

Uygulama yaygınlaşana kadar tanıtım, pazarlama ve özel servislere teknik destek verilmesi gibi hizmetler için maddi kaynak sağlanması gerekecektir. Uygulamanın yaygınlaşması ile müşterilerin özel servisler ve mobil uygulama aracılığıyla ödediği araç sorgulama ücretleri sayesinde uygulama yönetimi kendi ihtiyaçlarını karşılayabilecek duruma gelebilecektir. Zaman içerisinde blokzinciri ağı üzerinde kayıtlı bilgilerin çoğalması, özel servislere bilişim kaynağı ve disk maliyeti de oluşturacaktır. $\mathrm{Bu}$ masrafların da araç sorgulama ücretleri sayesinde karşılanabileceği düşünülmektedir. Elde edilen sorgulama gelirler ve tanıtım, müşteri hizmetleri teknik destek ve bakım gibi masraflar gibi mali işler uygulama yönetim birimi tarafından yürütülecektir.

\section{SONUC}

Merkezi bir yapıya sahip olmayan ya da üçüncü taraflara güvenmeyen veri sahibi paydaşlar arasında veri güvenliği ve şeffaflık gibi nedenlerden dolayı veri paylaşımı sağlanamamaktadır. Sosyo-ekonomik etkenlerden dolayı ülkemizde giderek artan ikinci el araç alışverişlerinde aracın geçmişteki bakım ve servis bilgilerine erişim her geçen gün daha önemli hale gelmektedir. Ama gerekli teknolojik altyapı ve güven sorunları nedeniyle doğru bilgiye erişim sağlamak mümkün olamamaktadır. Bu nedenle ikinci el araç müşterileri bu konuda büyük zorluklar ve mağduriyetler yaşamaktadır. Blokzinciri teknolojisi, özellikleri ve sunduğu firsatlar sayesinde paydaş birimlerin birbirine güvenmesini sağlamaktadır. Blokzinciri teknolojisi, dünya genelinde her geçen gün yeni uygulama alanları bulmaktadır. $\mathrm{Bu}$ çalışmada ikinci el araçların servis ve bakım kayıtlarının özel servisler aracılığıyla blokzinciri ağında dağıtık, şeffaf ve değiştirilemez olarak saklanması ve paylaşılmasına olanak veren araç cüzdanı uygulaması önerilmiştir.

Önerilen araç cüzdanı uygulaması blokzinciri ağ1 üzerinde çalıştığı için her özel servis hem veri sağlayıcı, hem denetleyici hem de veri merkezi olarak görev almaktadır. Bu yapıda her araç servisi tüm araç verilerinin bir kopyasını saklamaktadır. Bu sayede bir araç verisinin uygulama yönetimi ya da herhangi kötü niyetli bir servis tarafından değiştirilmesinin önüne geçilmektedir. Bu uygulama sayesinde verilerin saklanması ve doğrulanması tek bir merkez yerine tüm paydaşlar tarafindan yürütülmekte ve servisler, uygulama yönetimi ve araç sahipleri arasında bir güven ortamı oluşturulmaktadır.

Çalışmada ikinci el alışverişlerde aracın geçmiş kayıtlarına erişim noktasında yaşanan sorunlara ve blokzinciri teknolojisi hakkında genel bilgilere yer verilmiştir. Çalışmanın devamında önerilen uygulamanın teknik özellikleri, genel yapısı ve daha iyi anlaşılması için ekran tasarımlarına ilişkin bilgiler verilmiştir. Yeni bir teknoloji olan blokzincirinin araştırmacılar tarafından daha iyi anlaşılması için önerilen uygulamanın önemli bir bölümü olan blokzinciri kurulumu ve yönetimi hakkında teknik bilgi ve ekran görüntülerine yer verilmiştir. Son olarak önerilen uygulamanın sağlıklı bir şekilde hayata geçirilmesi, yaygınlaşması ve başarılı bir şekilde yönetilebilmesi için önerilere yer verilmiştir.

Önerilen araç cüzdanı uygulamasının bu alandaki karar vericiler, bilişim firmaları ve araştırmacılar için öncü bir çalışma olduğu ve gelecekte yapılacak çalışmalara 1şık tutacağı düşünülmektedir. 


\section{KAYNAKLAR}

[1] Indicata. (2020, 25 Ağustos). Temmuz 2020 Turkiye Otomotiv 2.el online pazar trend raporu. [Online]. Erişim: https://www.indicata.com.tr/hakkimizda/haberler-ve-medya/62-temmuz-2020turkiye-otomotiv-2-el-online-pazar-trend-raporu.

[2] Otomobil Distribütörleri Derneği. (2020, 25 Ağustos). Türkiye otomotiv pazarl. [Online]. Erişim:http://www.odd.org.tr/folders/2837/categorial1docs/2657/Sekt\%c3\%b6rel\%20De\%c4\%9ferlen dirme\%20Ocak\%202020.pdf.

[3] Y. Akçi, "İkinci el otomobil: tüketici bakışıla," Adlyaman Üniversitesi Sosyal Bilimler Enstitüsü Dergisi, c. 1, s. 1, ss. 329-362, 2016.

[4] M. Gabbott, "The role of product cues in assessing risk in second-hand markets," Eur. J. Mark., vol. 25 , no. 9, pp. 38-50, 1991.

[5] B. S. Duvan ve S. Ozturkcan, "An overview of blockchain technology: architecture, consensus, and future trends," 2017 IEEE 6th International Congress on Big Data, İzmir, Türkiye, 2009, ss. 557564.

[6] Başbakanlık Mevzuatı Geliştirme ve Yayın Genel Müdürlügü. (2020, 25 Ağustos). Resmi gazete. [Online]. Erişim:https://www.resmigazete.gov.tr/eskiler/2018/09/20180908-1.htm.

[7] S. Nakamato. (2020, 25 Ağustos). Bitcoin: a peer-topeer electronic cash system. [Online]. Erişim: https://bitcoin.org/bitcoin.pdf.

[8] Ş. Bahtiyar, O. Paksoy, E. Güldöşüren ve M. Pekel, "Öğrenciler arasında blokzincir farkındalığ1 üzerine bir araştırma," European Journal of Science and Technology, s. 18, ss. 424-434, 2020.

[9] R. Beck, "Beyond Bitcoin: The rise of blockchain world," Computer, vol. 51, no. 2, pp. 54-58, 2018.

[10] A. Reyna, C. Martín, J. Chen, E. Soler ve M. Díaz, "On blockchain and its integration with IoT. Challenges and opportunities," Future Generation Computer Systems, vol. 88, pp. 173-190, 2018.

[11] Z. Zheng, S. Xie, H. Dai, X. Chen ve H. Wang, "An overview of blockchain technology: architecture, consensus, and future trends," 6th International Congress on Big Data, BigData Congress, Bengaluru, India, 2018, ss. 557-564.

[12] M. Tanrıverdi, M. Uysal ve M. T. Üstündağ, "Blokzinciri teknolojisi nedir? Ne değildir?: Alanyazın incelemesi,” Bilişim Teknolojileri Dergisi, c. 12, s.3, ss. 203-217, 2019.

[13] T. Aste, P. Tasca ve T. Di Matteo, "Blockchain technologies: the foreseeable 1mpact on society and industry," Computer, vol. 50, no. 9, pp. 18-28, 2017.

[14] H. N. Dai, Z. Zheng ve Y. Zhang, "Blockchain for internet of things: a survey," IEEE Internet Things Journals, vol. 6, no. 5, pp. 8076-8094, 2019.

[15] V. Buterin.(2020, 25 Ağustos). On public and private blockchains. [Online]. Erişim: https://blog.ethereum.org/2015/08/07/on-public-and-private-blockchains.

[16] D. Puthal, N. Malik, S. P. Mohanty, E. Kougianos ve G. Das, "Everything you wanted to know about the blockchain: 1ts promise, components, processes, and problems," IEEE Consumer Electronics 
Magazine, vol. 7, no. 4, pp. 6-14, 2018.

[17] R. Anascavage ve N. Davis. (2020, 25 Ağustos). Blockchain technology: a literature review. [Online]. Erişim:https://ssrn.com/abstract=3173406 or http://dx.doi.org/10.2139/ssrn.3173406.

[18] Intelligenthq. (2020, 25 Ağustos). How Governments in Sweden, Denmark and Estonia are adopting Blockchain and AI. [Online]. Erişim: https://www.intelligenthq.com/how-governments-areadopting-blockchain-and-ai-in-advanced-economies-part-2.

[19] D. Puthal, N. Malik, S. P. Mohanty, E. Kougianos ve G. Das, "Everything you wanted to know about the blockchain: its promise, components, processes, and problems," IEEE Consumer Electronics Magazine, vol.7, no. 4, pp. 6-14, 2018.

[20] V. Hassija, M. Zaid, G. Singh, A. Srivastava, ve V. Saxena, "Cryptober: a blockchain-based secure and cost-optimal car rental platform," The 12th International Conference on Contemporary Computing, India, ss 1-6.

[21] N. H. Kim, S. M. Kang ve C. S. Hong, "Mobile charger billing system using lightweight Blockchain," Asia-Pacific Network Operations and Management Symposium: Managing a World of Things, Seul, Kore, 2017, ss. 374-377.

[22] M. Pustišek, A. Kos ve U. Sedlar, "Blockchain based autonomous selection of electric vehicle charging station," International Conference on Identification, Information and Knowledge in the Internet of Things, Beijing Çin, 2018, ss. 217-222.

[23] S. Xia, F. Lin, Z. Chen, C. Tang, Y. Ma ve X. Yu, "A bayesian game based vehicle-to-vehicle electricity trading scheme for blockchain-enabled internet of vehicles," IEEE Transactions on Vehicular Technology, vol. 69, no. 7, pp. 2020.

[24] K. Kim, T. Kim, and I. Y. Jung, "Blockchain-based Information Sharing between Smart Vehicles for Safe Driving,” IEEE Vehicular Technology Conference, Belçika, 2020, ss. 1-2.

[25] M. P. Hossain, M. Khaled, S. A. Saju, S. Roy, M. Biswas ve M. A. Rahaman, "Vehicle Registration and Information Management using Blockchain based Distributed Ledger from Bangladesh Perspective," IEEE Region 10 Symposium, TENSYMP, Pakistan, 2020, ss. 900-903.

[26] M. Demir, O. Turetken, and A. Ferworn, "Blockchain based transparent vehicle insurance management," 6th International Conference on Software Defined Systems, İtalya, 2019, ss. 213-220.

[27] Linux Foundation. (2020, 25 Ağustos). Hyperledger Project. [Online]. Erişim: https://www.hyperledger.org/.

[28] MultiChain. (2020, 25 Ağustos). Open source blockchain platform. [Online]. Erişim:https://www.multichain.com/.

[29] F. A. Abadi, J. Ellul ve G. Azzopardi, "The Blockchain of things, Beyond Bitcoin : A systematic review," IEEE International Conference on Internet of Things (iThings) and IEEE Green Computing and Communications (GreenCom) and IEEE Cyber, Physical and Social Computing (CPSCom) and IEEE Smart Data (SmartData), Kanada, 2018, ss. 1666-1672.

[30] K-Test Otomotiv. (2020, 25 Ağustos). Egzoz emisyon cihazları. [Online]. Erişim:http://www.ktest.com.tr/tr/urun.asp?uid=2. 